\title{
Power Efficiency Analysis of a Multi-Oscillated Current Resonant Type DC-DC Converter
}

\author{
Tadahiko SATO *, Ryu ARAKI *, Hiroyuki OTA *, \\ Nobuhiro HIGASHI**, Yoichi ISHIZUKA ** and Hirofumi MATSUO ** \\ * Fuji Electric Device Technology Co., Ltd. \\ 4-18-1 Tsukama, Matsumotoshi, Nagano, 565-0456 Japan \\ Tel.: +81-263-25-2765, Fax.: +81-263-28-8549 \\ E-mail: oota-hiroyuki@fujielectric.co.jp \\ ** Graduate School of Science and Technology, Nagasaki University \\ 1-14 Bunkyo-Machi, Nagasaki-shi, Nagasaki, 852-8521 Japan \\ Tel.: +81-95-819-2551, Fax.: +81-95-819-2551 \\ E-mail: h-matsuo@nagasaki-u.ac.jp
}

\begin{abstract}
This paper deals with an analysis of the power efficiency of a multi-oscillated current resonant type DC-DC converter. The current resonant type converter employs generally the pulse frequency modulation. For this reason, the magnetizing current through the converter causes not only a power loss under a light load, but also a loss during stand-by. In order to solve these problems, a multi-oscillated current resonant type DC-DC converter has been proposed, and revealed the advantage of its control method which can reduce power loss under light load and keep low switching noise. An analytical relationship of among states, operating mode and efficiency characteristics of this converter are defined. As a result, it was confirmed that for this converter, the output power depends on the voltage of resonant capacitor, and consequently, it is important to determine constants of resonant capacitor and inductance of transformer. The maximum efficiency is $\mathbf{9 5 . 4 \%}$ with the magnetizing inductance $1.8 \mathrm{mH}$.
\end{abstract}

\section{INTRODUCTION}

A switching power supply system with the high efficiency, small size, low noise and low cost, is requested in many areas of portable electronics systems such as personal computers, cellular phones, flat panel displays and so forth. In switching power supply systems, generally the pulse frequency modulation has been applied to current resonant type converters $[1,2]$.

However, these types of converter have problems, in which a magnetizing current through the converter causes a loss of power under the light load and stand-by conditions. Consequently, the small size required for this type of converter cannot be achieved, because an auxiliary source is necessary in the stand-by mode.

In order to solve these problems, a multi-oscillated current resonant type DC-DC converter has been proposed, and revealed the advantage of its control method which can reduce the power loss under light load and standby conditions, and keep low noise by using both pulse width modulation (PWM) and pulse frequency modulation (PFM) control modes [3-5].

This paper defines an analytical relationship among states, operating mode and efficiency characteristics of this proposed converter by considering to the currents of primary and secondary sides. Furthermore, the influence of a magnetizing inductance is clarified.

\section{Circuit CONFIGURATION AND OPERATING PRINCIPLE}

Figures 1 and 2 show the proposed multi-oscillated current resonant DC-DC converter and the timing chart, respectively. This converter consists of a half-bridge circuit, whose switches $\mathrm{Q}_{1}$ and $\mathrm{Q}_{2}$ are operated by a multioscillated current resonant driven by an IC with pulsewidth modulation (PWM), and an auxiliary winding $\mathrm{N}_{\mathrm{P} 2}$ of the transformer, respectively.

By applying a gate voltage to $\mathrm{Q}_{1}$ and $\mathrm{Q}_{2}$ at turn-on and turn-off, switching power losses are reduced due to the zero-voltage switching (ZVS) and zero-current switching (ZCS). In the isolated transformer $\mathrm{T}_{\mathrm{r}}$, the primary winding $\mathrm{N}_{\mathrm{P} 1}$ is loosely coupled to the secondary windings $\mathrm{N}_{\mathrm{S} 1}$ and $\mathrm{N}_{\mathrm{S} 2}$, for in which the voltage of the leakage inductance is relatively large. Because of the resonant circuit with this leakage inductance and the resonant capacitor, the switching power losses of $\mathrm{Q}_{1}$ and $\mathrm{Q}_{2}$ are reduced.

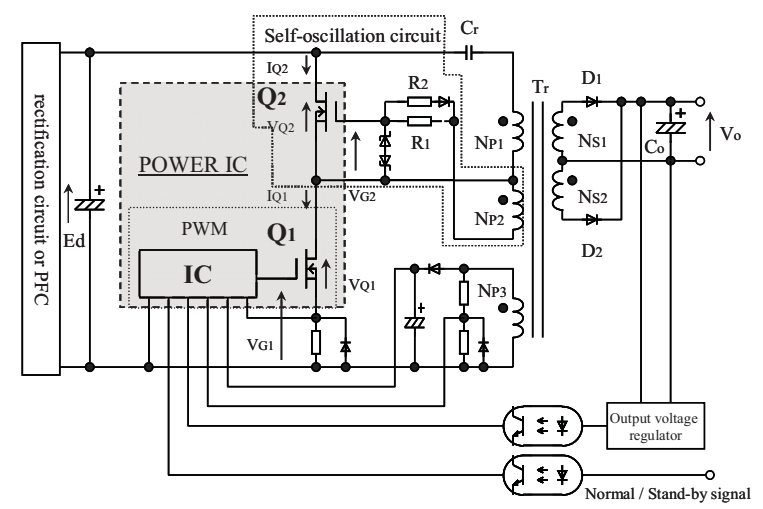

Figure 1. Circuit configuration 


\section{ANALYSIS OF STATES AND OPERATING MODES}

Figure 3 shows the equivalent circuits of the converter shown in Fig.1, which is divided into eight behavior states. Taking into account the combination of the eight states of behavior, they are further divided into four operating modes [5-7].

Figure 4 shows the simulated waveforms of the current and voltage for the four operating modes. From the results, the operating modes appear in the order of I, II, III and IV when the load current is varied from a light load to the heavy load.

The operating modes I and II mainly appear at light load. The energy in $\mathrm{C}_{\mathrm{r}}$ is discharged when the $\mathrm{Q}_{1}$ turns off and $\mathrm{Q}_{2}$ turns on, and charged by applying the output voltage $E_{d}$ of the $P F C$ when the $Q_{1}$ turns on and $Q_{2}$ turn off. Therefore, the energy is discharged to the secondary side through the transformer. However, because of the magnetizing inductance $\mathrm{L}_{\mathrm{m}}$ is set relatively large when there is shortage of the energy discharged from $\mathrm{C}_{\mathrm{r}}$, operating state 7 appears, in which there is no discharging interval to the secondary side.

In mode III, a ripple is reduced and smoothed by the leakage inductance $\mathrm{L}_{12}$ of the secondary winding and the output capacitor $\mathrm{C}_{\mathrm{o}}$ because the current flows continuously through $\mathrm{D}_{1}$ and $\mathrm{D}_{2}$, alternately.

The Mode IV appears when the duty ratio is almost over $50 \%$. In this mode, the state 8 appear where the power is not applied to the secondary side even when $Q_{1}$ turns on.

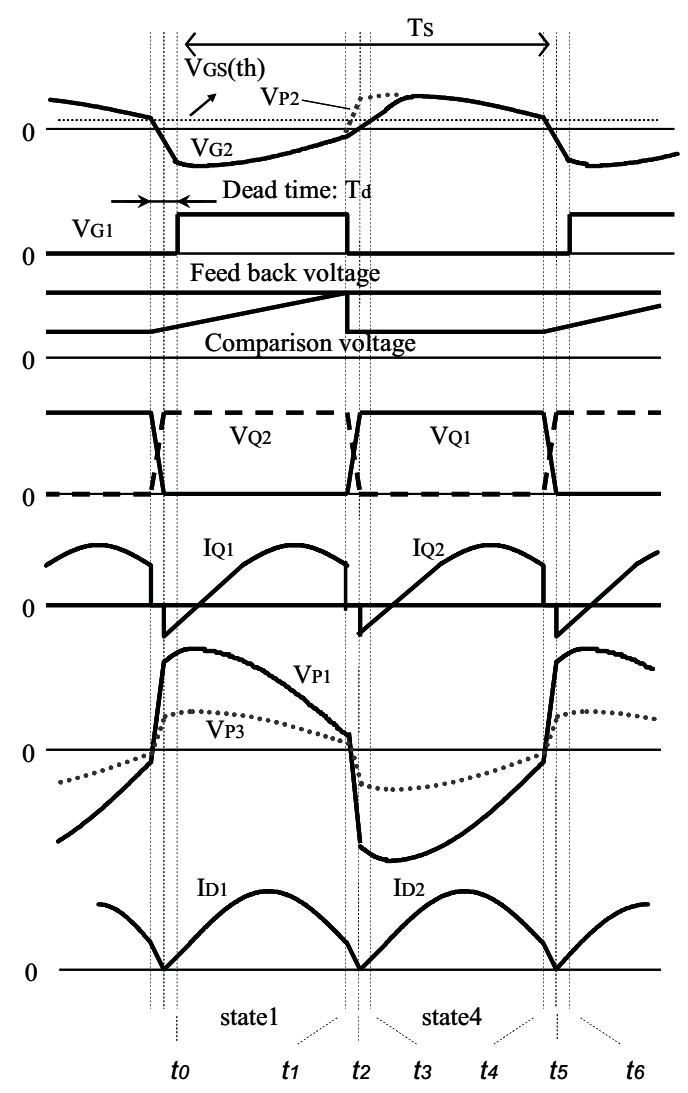

Figure 2. Timing chart

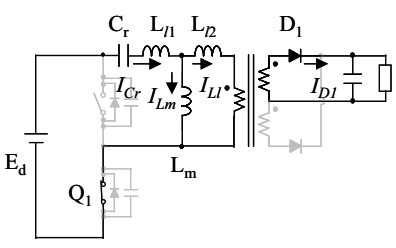

(a) State1

$$
\begin{array}{llll}
\mathrm{C}_{\mathrm{r}} & \mathrm{L}_{l 1} & \mathrm{~L}_{l 2}
\end{array}
$$

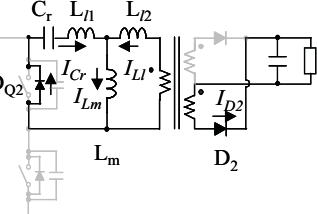

(c) State3

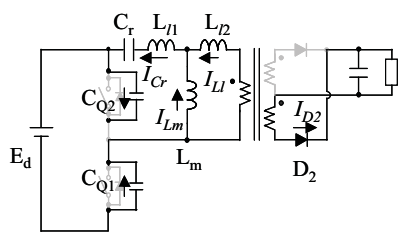

(e) State5

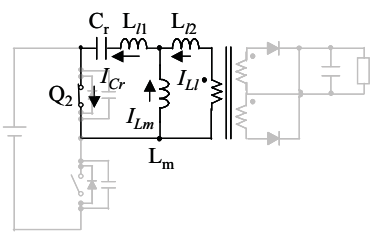

(g) State7

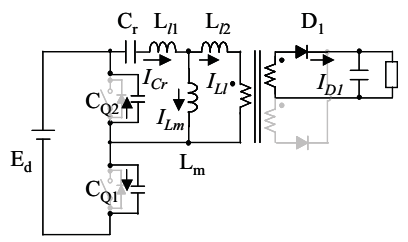

(b) State 2

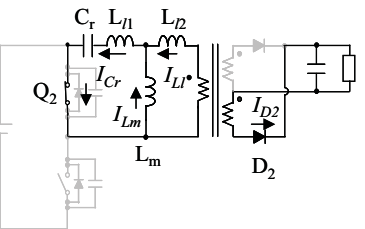

(d) State4

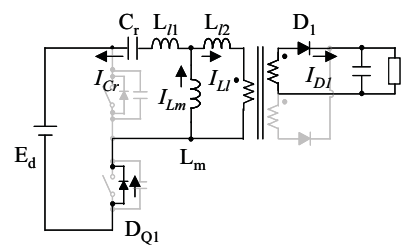

(f) State6

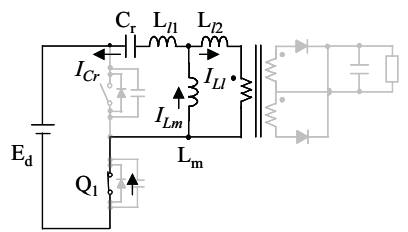

(h) State 8

Figure 3. Equivalent circuits and operation states

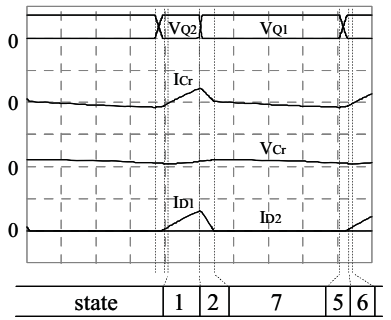

(a) Mode I

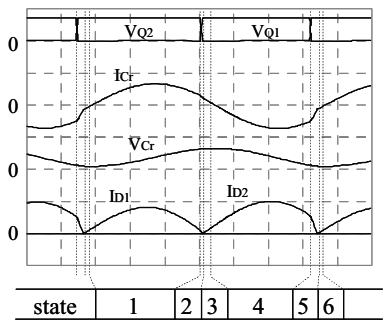

(c) Mode III

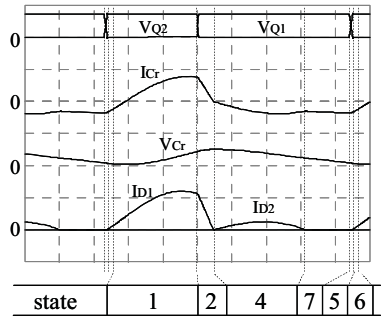

(b) Mode II

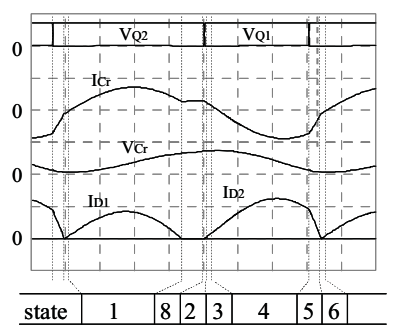

(d) Mode IV

Figure 4. Operation modes 


\section{RESUlT OF POWER EFFICIENCY ANALYSIS}

In this converter, the output power is controlled by transmitting the energy stored in the resonant capacitor. It has been clarified in the recent papers that voltage amplitude of $\mathrm{C}_{\mathrm{r}}$ is important to determine the output power [5-7] In the Mode III, assuming that the voltage amplitude of $\mathrm{C}_{\mathrm{r}}$ is equal to the output voltage $E_{d}$ of the PFC when the maximum output power is received from $C_{r}$ in the converter, the maximum output can be approximated by $\mathrm{E}_{\mathrm{d}}$.

$$
P\left(C_{r}\right)=C_{r} \cdot E_{d}^{2} \cdot f_{r}
$$

where $\mathrm{f}_{\mathrm{r}}$ is the resonant frequency, given by

$$
f_{r}=\frac{1}{2 \pi \sqrt{C_{r} \cdot L_{r}}}
$$

where $\mathrm{L}_{\mathrm{r}}$ is the inductance of primary side at the shortcircuit of the secondary winding, given by

$$
L_{r}=L_{l 1}+\frac{L_{l 2} \cdot L_{m}}{L_{l 2}+L_{m}}
$$

Therefore, it is important to determine the parameters $E_{d}, C_{r}$ and $L_{r}$ for realizing the maximum power from $C_{r}$. In addition, a magnetizing inductance $\mathrm{L}_{\mathrm{m}}$ is supposed to be sufficiently large.

The relations between the power efficiency and each circuit parameters are investigated as follows.

\section{A. Power Efficiency Analysis with Effective Currents}

Fig.5 (a), (b) and (c) show the power efficiency and a duty ratio of switch $\mathrm{Q}_{1}$, taking $\mathrm{E}_{\mathrm{d}}, \mathrm{C}_{\mathrm{r}}$ and $\mathrm{L}_{\mathrm{r}}$ as parameters, respectively. The experimental conditions are as follows: $\mathrm{E}_{\mathrm{d}}=350 \mathrm{~V}, 360 \mathrm{~V}, 380 \mathrm{~V}, \mathrm{C}_{\mathrm{r}}=12 \mathrm{nF}, 15 \mathrm{nF}, 18 \mathrm{nF}, \mathrm{L}_{\mathrm{r}}=180 \mu \mathrm{H}$, $320 \mu \mathrm{H}, 220 \mu \mathrm{H} 400 \mu \mathrm{H}, \mathrm{L}_{\mathrm{m}}=13 \mathrm{mH}, 18 \mathrm{mH}$, a output current of $\mathrm{I}_{\mathrm{o}}=1 \mathrm{~A}-7 \mathrm{~A}$.
It is seen in Fig. 5 that the power efficiency becomes max when duty is $50 \%$ even if $E_{d}, C_{r}$ and $L_{r}$ varied. Fig.6 shows the switching frequency characteristics, taking $\mathrm{E}_{\mathrm{d}}$, $\mathrm{C}_{\mathrm{r}}$ and $\mathrm{L}_{\mathrm{r}}$ as parameters. The experimental conditions are same as in Fig.5. In Fig6, the switching frequency is almost constant in the current range of $3 \mathrm{~A}$ or more. In this case, the duty is over $35 \%$. Therefore, this converter achieves high efficiency when duty is $50 \%$. And the influence of the switching loss can be disregarded because the switching frequency becomes constant at the mode III where duty is approximately $50 \%$.

Then, as follows discussing the conduction loss, the stored energy in $\mathrm{C}_{\mathrm{r}}$ is composed of the current transmitted to the secondary side $\mathrm{I}_{\mathrm{o}}$ and the current circulated through the only primary side $\mathrm{I}_{\mathrm{CP}}$. These relations are

$$
n \cdot\left(I_{C r}-I_{C P}\right)=I_{o}
$$

where $\mathrm{n}$ is the winding ratio of the primary side and the secondary side,

$$
n=T_{N P} / T_{N S}
$$

where, $\mathrm{T}_{\mathrm{NP}}$ is the winding number of primary side, and $\mathrm{T}_{\mathrm{NS}}$ is the winding number of secondary side.

Fig. 7 shows an analysis of the effective currents $\mathrm{I}_{\mathrm{CP}(\mathrm{RMS})}$, $\mathrm{I}_{\mathrm{o}(\mathrm{RMS})}$. These currents in Fig.7 are normalized by the output current $\mathrm{I}_{\mathrm{o}}$. It is seen in Fig.7 that the circulated current of primary side is almost constant and comparatively small even when duty is changed. The effective current of secondary side is minimized when duty is almost $50 \%$, in which the proposed converter is able to minimize the consumption loss.

As a result, it is confirmed that the maximum power efficiency is achieved when duty is about $50 \%$.

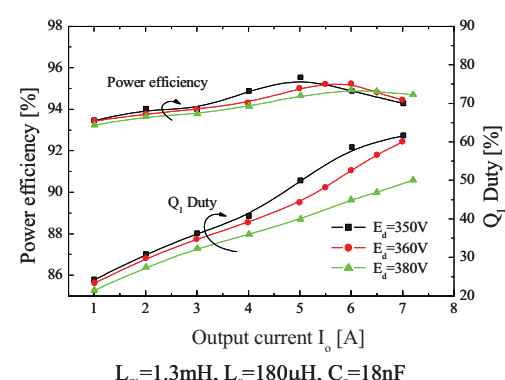

(a) $\mathrm{E}_{\mathrm{d}}$

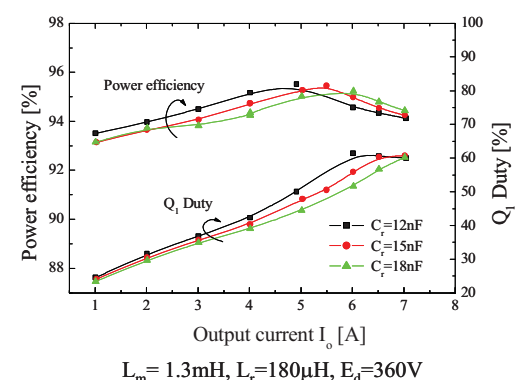

(b) $\mathrm{C}_{\mathrm{r}}$

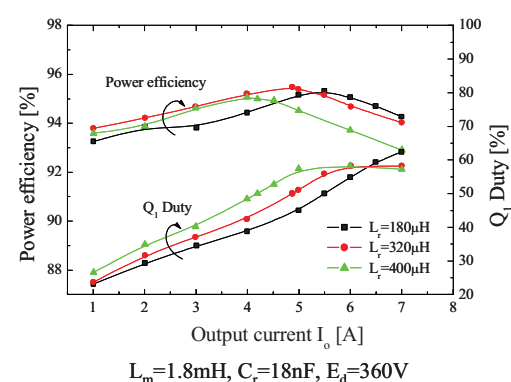

(c) $\mathrm{L}_{\mathrm{r}}$

Figure 5. Power efficiency and duty cycle characteristics

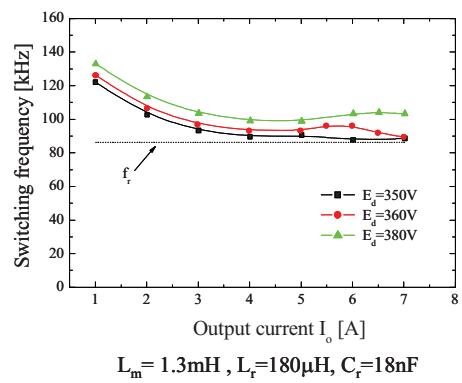

(a) $E_{d}$

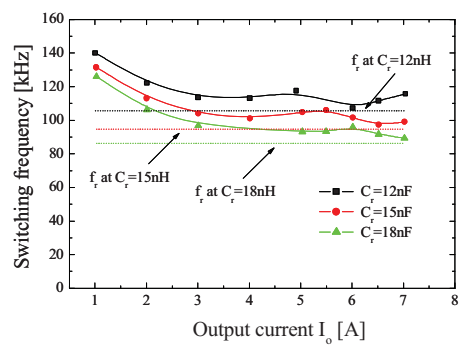

$\mathrm{L}_{\mathrm{m}}=1.3 \mathrm{mH}, \mathrm{L}_{\mathrm{r}}=180 \mu \mathrm{H}, \mathrm{E}_{\mathrm{d}}=360 \mathrm{~V}$

(b) $\mathrm{C}_{\mathrm{r}}$

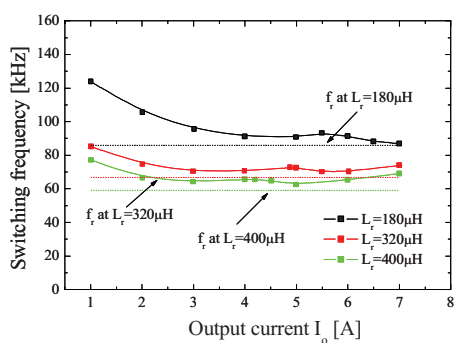

$\mathrm{L}_{\mathrm{m}}=1.8 \mathrm{mH}, \mathrm{C}_{\mathrm{r}}=18 \mathrm{nF}, \mathrm{E}_{\mathrm{d}}=360 \mathrm{~V}$

(c) $\mathrm{L}_{\mathrm{r}}$

Figure 6. Switching frequency characteristics 


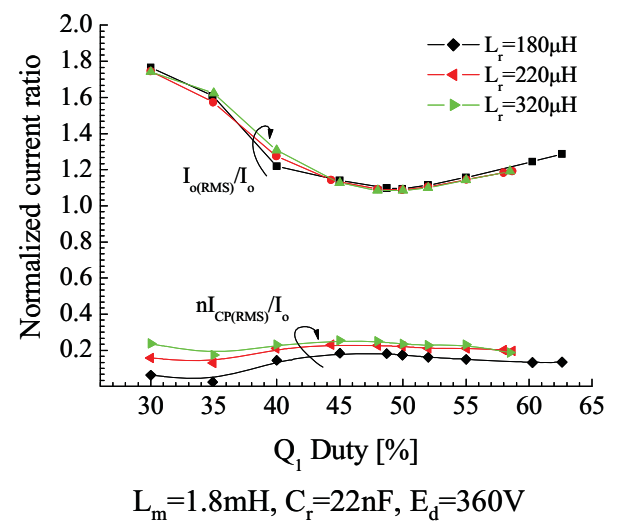

Figure 7. $\mathrm{Q}_{1}$ duty-normalized current ratio

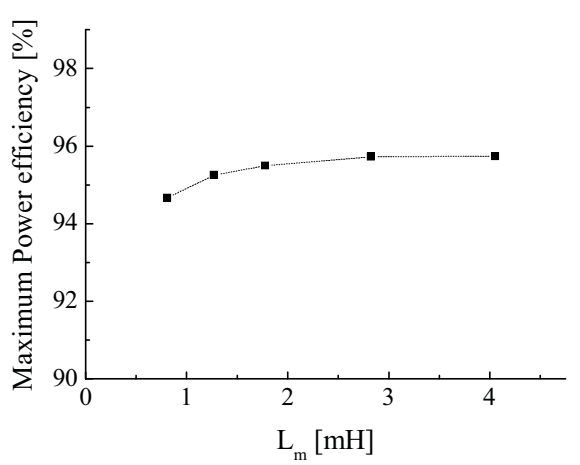

Figure $8 . \mathrm{L}_{\mathrm{m}}$ Vs. maximum power efficiency

\section{B. The Design of Magnetizing Inductance $L_{m}$}

A feature of this converter is able to suppress the rise of the frequency at light load because of the proposed control method.

Therefore, $\mathrm{L}_{\mathrm{m}}$ can be designed relatively large compared with PFM controlled current resonant type converter.

In equation (1), a magnetizing inductance $\mathrm{L}_{\mathrm{m}}$ is assuming that it is sufficiently large. Then the relation between $\mathrm{L}_{\mathrm{m}}$ and power efficiency is investigated.

Figure 8 shows a power efficiency characteristics at duty is $50 \%$ when $\mathrm{L}_{m}$ is changed. It is found that the maximum power efficiency improves when $\mathrm{L}_{\mathrm{m}}$ is enlarged.

Figure 9 shows an analysis of the effective currents $\mathrm{I}_{\mathrm{CP}(\mathrm{RMS})}$ and $\mathrm{I}_{\mathrm{o}(\mathrm{RMS})}$ at the duty $50 \%$. In a word, it is the load at the maximum efficiency point. These currents in Fig. 9 are also normalized by the output current $\mathrm{I}_{\mathrm{o}}$ same as Fig.7.

It can be seen in Fig. 9 that the circulated current of primary side can be decreased with keeping the effective currents of secondary side is almost constant when $\mathrm{L}_{m}$ is increased.

However, at heavy load, the switch Q2 is not able to achieve ZVS when $\mathrm{L}_{\mathrm{m}}$ becomes large.

Figure 10 shows maximum output current $\mathrm{I}_{\text {omax }}$ and a range where $\mathrm{Q}_{2}$ is able to achieve ZVS. The experimental conditions are as follows:

$E_{d}=360 \mathrm{~V}$, output voltage $V_{o}=24 V$, output current $\mathrm{I}_{\mathrm{o}}=1 \mathrm{~A}-7 \mathrm{~A}, \quad \mathrm{C}_{\mathrm{r}}=22 \mathrm{nF}, \quad \mathrm{L}_{\mathrm{r}}=320 \mu \mathrm{H}, \quad \mathrm{L}_{\mathrm{m}}=0.8 \mathrm{mH}, \quad 1.3 \mathrm{mH}$, $1.8 \mathrm{mH}, 4.1 \mathrm{mH}$ and $\mathrm{C}_{\mathrm{Q} 1}=\mathrm{C}_{\mathrm{Q} 2}=170 \mathrm{pF}$.

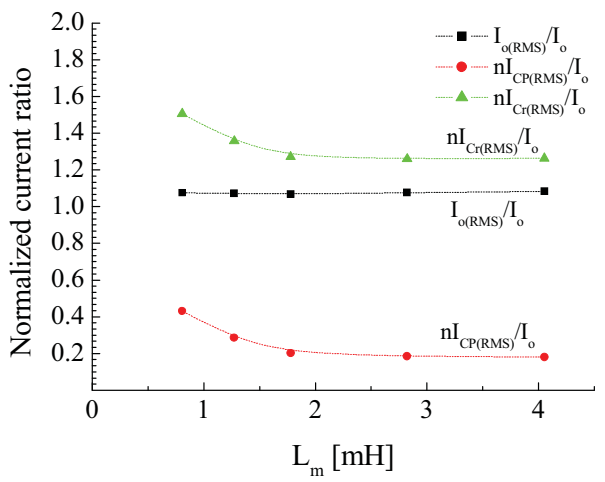

Figure 9. $\mathrm{L}_{\mathrm{m}}$ vs. normalized current ratio

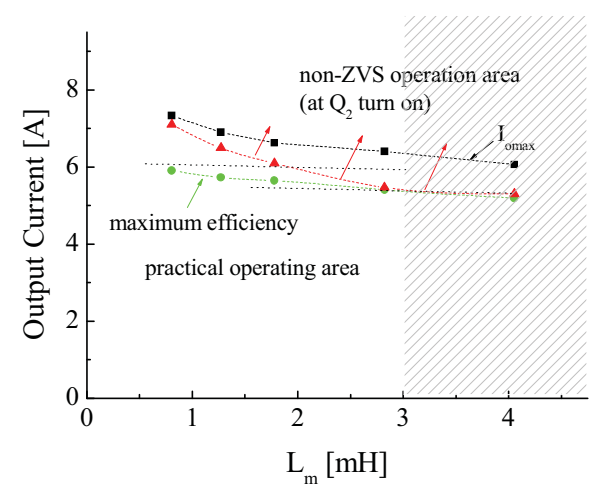

Figure $10 . \mathrm{L}_{\mathrm{m}}$ vs. normalized current ratio

Non-ZVS is observed in the area of $\mathrm{L}_{\mathrm{m}}=3 \mathrm{mH}$ or more from figure 10 . It is found that $\mathrm{L}_{\mathrm{m}}=3 \mathrm{mH}$ or less is preferable to achieve a ZVS at the maximum efficiency in the rated load. And $\mathrm{L}_{\mathrm{m}}=2 \mathrm{mH}$ or less is preferable to achieve ZVS at maximum power, if it is defined as $110 \%$ from rated load.

Therefore the preferable design of $\mathrm{L}_{\mathrm{m}}$ is about $2 \mathrm{mH}$ or less from the viewpoint of ZVS operation, maximum power efficiency and maximum output power. It can be seen in Fig10 that the maximum power efficiency is $95.4 \%$ with $\mathrm{L}_{\mathrm{m}}$ is $1.8 \mathrm{mH}$.

\section{CONCLUSION}

This paper is conclude as follows,

(1) This converter is controlled by a combination of selfoscillation and a separated oscillation.

(2) This converter has eight states and four operating modes.

(3) This opposed converter is able to achieve high efficiency at duty of switch $\mathrm{Q}_{1}$ is $50 \%$.

(4) Power efficiency improves when $\mathrm{L}_{\mathrm{m}}$ becomes large.

(5) It is necessary to select $\mathrm{L}_{\mathrm{m}}$ within the range where $\mathrm{Q}_{2}$ is able to achieve ZVS.

(6) It is necessary to select $\mathrm{L}_{\mathrm{m}}$ about $2 \mathrm{mH}$ from the viewpoint of ZVS operation, maximum power efficiency and maximum output power.

(7) The maximum power efficiency is $95.4 \%$ with the magnetizing inductance $1.8 \mathrm{mH}$. 


\section{REFERENCES}

[1] M. Gekinozu, K. Kuroki, K. Mori, T. Fujita "Self-oscillated type current resonant DC/DC converter", IEICE Technical Report, EE99-58, pp.33-38. 2002.

[2] Y. Nishikawa, T. Nozawa, S. Igarashi, K. Kuwahara, N. terasawa "Multi-oscillated Current Resonant Converter", Annual Conference Record of EEEJ, Vol.4, pp.157-158, 2002.

[3] Y. Nishikawa, T. Nozawa, S. Igarashi, K. Kuwahara, N. Nozawa, H. Ota "A control method that reduce the conversion loss at a light load", Annual Conference of Japan, Industry Application Society, pp.631-632, 2002.

[4] K. Kuwahara, H. Ota "On the Output Increase of a Series Resonant DC-DC Converter", IEICE Technical Report, Vol.105, no.45, EE2005, pp.35-40, 2005.

[5] R.Araki, O. Matsuo, H. Ota, M. Tuji, Y. Ishizuka, H. Matsuo "Static Analysis of Multi-Oscillated Current Resonant Type DCDC Converter", IEICE Technical Report, EE2006-31, pp13-18, 2006.

[6] N. Higashi, R. Araki, O. Matsuo, H. Ota, Y. Ishizuka, H. Matsuo "Multi-Oscillated Current Resonant Type DC-DC Converter", IEICE General Conference, pp.S-45-46, 2007.

[7] O. Matsuo, H. Matsuo, Y. Ishizuka, H. Ota "Analysis of a New Multi-Oscillated Current Resonant Type DC-DC Converter", IEEE INTELEC'07, pp.348-354, 2007. 